\title{
CYST OF THE INCARCERATED IRIS* FIRST REPORT OF COMPLICATION FOLLOWING CATARACT EXTRACTION
}

BY

\author{
KAILASH NATH \\ M.U. Institute of Ophthalmology and Gandhi Eye Hospital, Aligarh, India
}

IRIS incarceration following cataract extraction is a fairly common accident, which occurs in 1 to 3 per cent. of cases. If the operator fails to attend to it promptly, it may lead to an eccentric pupil, iritis, shallow anterior chamber due to a leaking wound, secondary glaucoma, sympathetic ophthalmitis, and so on, especially if ballooning of the iris is present, giving rise to constant irritation.

Other small incarcerations, which may be inadvertently left at the time of operation or may occur on the first or second post-operative day, look very innocent in the beginning and are usually discovered at the first dressing. They are more likely to occur when a complete or broad iridectomy has been done, and the operator may ignore them if everything else appears normal.

The spontaneous formation of a cyst in one of these incarcerated portions of the iris has not hitherto been reported, although intra-ocular cystic growths from the iris are frequently seen, the majority of them after cataract operations. Some resemblance to the present case may be seen in a case reported by Charamis and Sfalgako (1935), in which an epithelial iris cyst in the anterior chamber grew out through the section after a combined extraction.

\section{Case Report}

A businessman aged 75 years had been operated on in a mobile eye camp at his home town of Amroha for cataract with chronic simple glaucoma in the left eye; 4 months later on January 3, 1963, he came to the Gandhi Eye Hospital, Aligarh, as he was not feeling comfortable.

Examination.- He had an immature senile cataract in the right eye. The iris was depigmented and a few pigmentary keratic precipitates were present. The fundus could not be seen even after dilatation of the pupil because of advanced lenticular changes. The ocular tension was normal and the visual acuity $3 / 60$.

The left eye had a sausage-shaped, translucent, subconjunctival, cystic swelling along the limbus in the upper nasal quadrant. The swelling started at the limbus a little above the 9 o'clock meridian and extended almost up to 12 o'clock on the cornea (Figure); it was about 4-5 mm. across and about $9 \mathrm{~mm}$. long. The conjunctiva covering the swelling was free and mobile, particularly on the outer side.

The Figure (opposite) shows the marking around the cyst where the conjunctiva appeared to be raised from the episcleral tissues. The space between the cyst and conjunctival covering, which was more evident in the lower temporal aspect of the cyst wall and was absent in the upper part, was filled with clear transparent fluid. The cyst wall was very thin and a cobweb of brownish pigment lay all along it. There was no communication between the cavity of the cyst and the anterior chamber.

\footnotetext{
* Received for publication February 11, 1963.
} 


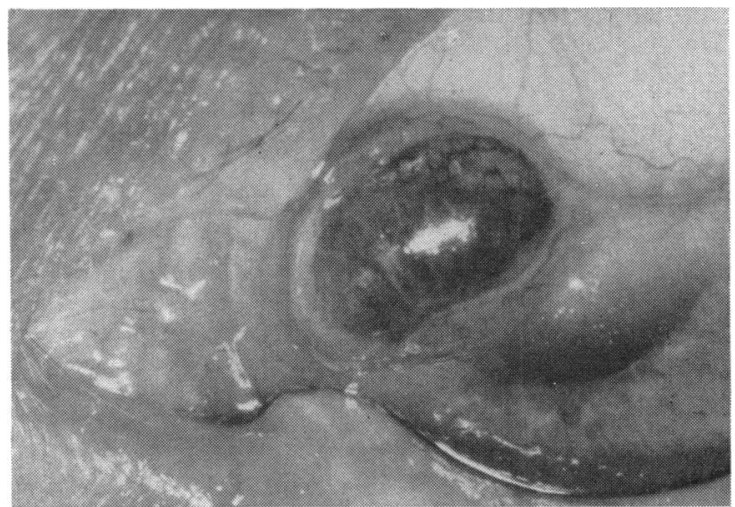

FigURE.-Slit-lamp photograph focused on subconjunctival cyst of incarcerated iris. The patient is looking down. A clear transparent subconjunctival space surrounds the cyst, more marked below. The elevation of the conjunctiva from the episclera is marked by a darkish line. The thin translucent wall of the cyst shows a cobweb-like pigmentation.

In this eye an intracapsular cataract extraction had been performed 4 months previously, by limbal section and broad iridectomy. The section was slightly irregular at 11 o'clock (Figure) near the upper end of the cyst where the upper and inner edge of the iris had become incarcerated. The cornea near this section was hazy. The anterior chamber was well formed. There were a few pigmentary keratic precipitates. The iris was brownish and a little depigmented. The upper nasal edge of the cut iris was pulled up towards the section at 11 o'clock. Vitreous adhered to the posterior lip of the section at 12 o'clock, and a few organizing strands extended deep into the vitreous. The rest of the vitreous surface was well formed.

Fundus examination revealed a pale, cupped, atrophic disc. The ocular tension had been normal since the operation. The visual acuity was $1 / 60$ and did not improve beyond 6/60 with $+11 \mathrm{D}$ sph., $+2 \mathrm{D}$ cyl., axis $180^{\circ}$.

The patient was advised to enter hospital for excision of the cyst, but refused because he was urgently needed at home.

\section{Comment}

Cysts of the iris may be of the implantation, spontaneous, congenital, or parasitic type. Implantation cysts are the commonest and may occur after cataract extraction or foreign body implantation, being caused by the implantation of corneal epithelium on the iris.

Spontaneous cysts are less common and quite a few eyes have been removed in the past on suspicion of their being malignant melanomata (Coats, 1907).

Congenital and parasitic cysts are extremely rare.

As no pathological investigation could be made it is difficult to establish the type of cyst involved in this case. The clinical features point to its being a spontaneous cyst from the anterior layers of the iris. The cobweb of pigment dispersed round the cyst wall prevents its being described as an implantation cyst, and suggests that it arose from the mesostromal layers of iris.

\section{Summary}

In spite of the large number of iris incarcerations that occur in the course of intra-ocular surgery, no cysts arising from the incarcerated iris have hitherto been reported. 
A large subconjunctival cyst arising from the incarcerated iris after an intracapsular cataract extraction is reported in detail, and it is concluded that the cyst arose from the mesostromal layers of the iris.

The absence of reports of such cysts from the literature appears to be due to the action of the upper eyelids, which rupture the delicate cyst walls and stop them growing large enough to attract attention.

\section{REFERENCES}

Charamis, J., and Sfalgako (1935). Arch. Ophtal., 52, 167.

CoATs, G. (1907). Roy. Lond. Hosp. Rep., 17, 143.

WORTH, C. (1910). Ibid., 18, 52.

\section{ADDENDUM}

Since this paper was submitted the patient has been admitted to hospital (April 3, 1963) and the cyst excised (April 5, 1963). A histopathological examination showed it to be a mesostromal iris cyst. 